Запропоновано строгий формальний алгоритм побудови двоїстої задачі для різних випадків запису (загальна, основна, стандартна та канонічна) прямої задачі лінійного програмування.

На початку наведено означення пари двоїстих задач для стандартної форми запису прямої задачі лінійного програмування. Такий підхід обтрунтовується з тих позицій, що за часом така пара була означена периою, оскільки мала змістовну інтерпретацію.

Економічною інтерпретачією стандартної задачі є максимізація прибутку при виробництві та реалізацї деяких видів продукції. Такий підхід змістовно вказує на існування прямої задачі (I) та строго відповідної до неї двоїстої (спряженої) (II). Супутня до прямої задачі є задача про мінімізачію витрат.

Базовим поняттям теорї двоїстості в задачах лінійного програмування є той факт, що пара задач є взаємно спряженими отримання двоїстої від двоїстої призводить до прямої задачі.

Строгий підхід до отримання алгоритму складання двоїстої задачі грунтується на твердженні - двоїста задача від двоїстої є прямою (вихідною) задачею. Для різних пар двоїстих задач строго доводиться виконання такого твердження.

Існуючі схеми переходу від прямої задаиі до двоїстої носять змістовний характер. 3 огляду на цей факт, запропоновано та строго доведено алгоритм загального підходу до складання пар спряжених задач.

Формалізація розробленої схеми дозволяє легко отримувати пари відомих двоістих задач. Це дозволило запропонувати та довести істинність алгоритму побудови двоїстої задачі для довільної форми представлення прямої задачі

Ключові слова: лінійне програмування, пряма задача, двоїста задача, двоїстість, иільова функція, система обмежень, пари спряжених задач
UDC 517.8

DOI: $10.15587 / 1729-4061.2019 .175105$

\section{DEVELOPMENT OF A FORMAL ALGORITHM FOR THE FORMULATION OF A DUAL LINEAR OPTIMIZATION PROBLEM}

Ld. Chernova

$\mathrm{PhD}$, Associate Professor

Department of Information Control Systems and Technologies*

E-mail: myla-0108@mail.com

S. T i t o v

$\mathrm{PhD}$, Associate Professor

Department of Higher Mathematics*

E-mail: ss1-ss10@ukr.net

S. Chernov

Doctor of Technical Sciences, Professor Department of Project Management*

E-mail: 19chsk56@gmail.com

K. Koles nikova

Doctor of Technical Sciences, Professor

Department of Technology Management Taras Shevchenko National University of Kiyv Volodymyrska str., 60, Kyiv, Ukraine, 01033

E-mail: amberk4@gmail.com

Lb. Chernova

$\mathrm{PhD}$, Associate Professor

Department of Computer-aided Systems Software Support* E-mail: 19chls92@gmail.com

V. Gog u n s k i i

Doctor of Technical Sciences, Professor Department of Systems Management Life Safety

Odessa National Polytechnic University Shevchenka ave., 1, Odessa, Ukraine, 65044 E-mail: vgog@i.ua

*Admiral Makarov National University of Shipbuilding Heroiv Ukrainy ave., 9, Mykolayiv, Ukraine, 54025
Received date 30.06.2019 Accepted date 22.07.2019 Published date 29.08.2019
Copyright (C) 2019, Ld. Chernova, S. Titov, S. Chernov, K. Kolesnikova, Lb. Chernova, V. Gogunskii This is an open access article under the CC BY license (http://creativecommons.org/licenses/by/4.0)

\section{Introduction}

Linear programming is widely used to solve the problems of resource allocation [1], highest profit or least cost assessment [2], inventory management [3], formation of an optimal transportation plan [4], research identification [5], etc.

One approach to solving linear programming problems is to apply the duality principle, which is methodologically related to the theory of systems of dependent inequalities [4]. This aspect raises the concept of duality in linear programming (LP) problems to a general mathematical rigor. The key theorem in the LP theory is the Farkas-Minkowski theorem [6]. The theorem provides a necessary and sufficient condition for a linear inequality to be a conclusion of a finite system of linear inequalities. The importance of the theorem is that all basic facts of the linear programming theory [7] (including duality theory) can be obtained as conclusions of this theorem.

Known methods of primal to dual conversion are based on qualitative transformations and have substantial nature. Formalizing and proving the correctness of the algorithm for constructing a dual problem for an arbitrary form of presentation of a primal problem will make it easy to obtain correct pairs of known dual problems. 
The relevance of research is driven by requirements for simplifying solutions of linear programming problems based on the development of a formal algorithm of conversion of the primal problem to the dual linear optimization problem.

\section{Literature review and problem statement}

It can be said without exaggeration that the duality theory and the resulting pair of conjugate problems are crucial concepts in the LP theory. In the theory of sets, predicates, statements, in the algebra of events and geometry there are so-called duality theorems. According to certain rules, the primal theorem is put in correspondence with the dual theorem. In many cases, mathematical models of different systems are interpreted as discrete optimization problems [8]. Search for methods of exact or approximate solutions of such problems is performed taking into account their belonging to so-called $P$ and $N P$ problems (algorithms of polynomial and exponential solution) [7].

In the classical section of linear programming, such a pair of extreme problems is known. This is due to the peculiarity of convex sets - closed convex sets in a vector space can be described in two ways, both in the original $R^{n}$ and conjugate $R^{m}$ space. Existing schemes of conversion of the primal linear programming problem to dual have, as a rule, substantially economic nature and therefore cannot satisfy both economic and technical cybernetics, which are widely used in management models.

Combinatorial methods for accurate and practical solution of discrete optimization problems occupy one of the important places in obtaining optimum values for such problems [8]. For the implementation of solution algorithms, it is necessary to obtain an initial basis, estimates of optimality and improvement in case of non-optimality. Modern combinatorial methods for the practical solution of linear programming problems require the development of algorithms that allow obtaining an approximate solution with a guaranteed assessment of deviation from an optimum [9].

Algorithms of transformations in linear programming problems are an effective way of finding solutions to optimization problems [10]. If to perform the primal to dual operation, then such a technique will allow observing the allowable parameter set of the problem [11]. It is possible to obtain upper and lower bounds of the values of the objective function of the problem and dynamically evaluate the possibility of diversification of basic optimum variables with guaranteed accuracy [12]. In [13], the method of thermoeconomic optimization of energy-intensive linear systems on graphs is developed. The analysis of solution stability in the problems of duplicate detection in electronic documents is given in [14]. The complexity of displaying linear relationships in learning processes using Markov chains is explored in [15]. The performance of linear models for sports training is shown in [16].

In the above publications, as a rule, individual forms of presentation of linear programming problems for different cases (general, basic, standard and canonical forms) of primal problems are investigated and applied. At the same time, although many methods in this area have been developed and researched, there is a problem of creating effective models at the stage of solving systems of equations for the mathematical description of complex systems [8].

Approaches commonly used to solve LP problems are often aimed at simplification through the use of specific constraints [5], iterative search for solutions of equation systems [12], decomposition of systems using graphs [13]. The specified methods of solving linear equation systems are focused on using additional transformation of mathematical description of systems with the construction of unique algorithms of problem solution [15]. The problematic issue of LP problems is the lack of strategies for generalizing the search for solutions. The essence of this study is that it is proposed to choose the simplest form of the problem, taking into account the existing conjugated dual mappings of the problem at the stage of problem formulation.

The dual LP problem is obtained by inversion of the objective function and variables of the original problem. If the objective function of the original problem is set to a maximum, then the objective function of the dual problem is set to a minimum. Primal to dual conversion should be carried out using a certain formalized algorithm. The presence of pairs of conjugate dual LP problems allows choosing a rational solution strategy for all forms in view of the computing complexity of solution. All possible transformations of the original problem should improve the solution of systems of mathematical description equations.

\section{The aim and objectives of the study}

The aim of the study is to obtain a formal primal to dual algorithm and to strictly prove these rules. This will allow choosing a simpler dual problem to solve linear programming problems more easily.

To achieve this aim, the following objectives were set:

- to prove the conjugated nature for existing pairs of dual problems;

- to present the operation of primal to dual conversion in a general form.

\section{Determination of duality for standard form of linear programming problem}

Suppose that the primal (original) linear programming problem is presented in standard form [17].

Let us call the following LP problem a standard problem:

$$
\mathbf{I}: \mid \begin{aligned}
& W_{\mathrm{I}}=\sum_{j=1}^{n} c_{j} x_{j} \rightarrow \max , \\
& \Omega_{\mathrm{I}}: \sum_{j=1}^{n} a_{i j} x_{j} \leq b_{i}, i=1, \ldots, m, \\
& x_{j} \geq 0, j=1, \ldots, n,
\end{aligned}
$$

or in matrix form:

$$
\mathbf{I}: \mid \begin{aligned}
& W_{\mathrm{I}}=C X \rightarrow \max , \\
& \Omega_{\mathrm{I}}: A X \leq B, \\
& X \geq 0 .
\end{aligned}
$$

The dual or conjugate problem to it is a problem of the following form:

$$
\text { II : } \mid \begin{aligned}
& W_{\mathrm{II}}=\sum_{i=1}^{m} b_{i} y_{i} \rightarrow \min , \\
& \Omega_{\mathrm{II}}: \sum_{i=1}^{m} a_{i j} y_{i} \geq c_{j}, j=1,2, \ldots, n, \\
& y_{i} \geq 0, i=1,2, \ldots, m,
\end{aligned}
$$


or in matrix form:

$$
\text { II : } \mid \begin{aligned}
& W_{\mathrm{II}}=Y B-\min , \\
& \Omega_{\mathrm{II}}: Y A \geq C^{T}, \\
& Y \geq 0 .
\end{aligned}
$$

For convenience, we introduce and comment on the following notations:

$$
\mathbf{c}=C=c=\left[c_{1}, c_{2}, \ldots, c_{n}\right],
$$

$C \in \mathbf{R}^{n}$ - coefficients of the objective function $W_{\mathrm{I}}$ of the primal LP problem;

$$
\mathbf{x}=X=x=\left[\begin{array}{c}
x_{1} \\
x_{2} \\
\vdots \\
x_{n}
\end{array}\right]=\left[x_{1}, x_{2}, \ldots, x_{n}\right]^{\mathrm{T}}
$$

$X \in \mathbf{R}^{n}$ - variable (unknown) values (basis) of the primal LP problem; I - symbol of the primal problem; II - symbol of the dual problem;

$$
A=\left[a_{i j}\right]_{(m \times n)}=\left[\begin{array}{ccccccc}
a_{11} & a_{12} & a_{13} & \cdots & a_{1 j} & \cdots & a_{1 n} \\
a_{21} & a_{22} & a_{23} & \cdots & a_{2 j} & \cdots & a_{2 n} \\
a_{31} & a_{32} & a_{33} & \cdots & a_{3 j} & \cdots & a_{3 n} \\
\vdots & \vdots & \vdots & \vdots & \vdots & \vdots & \vdots \\
a_{i 1} & a_{i 2} & a_{i 3} & \cdots & a_{i j} & \cdots & a_{i n} \\
\vdots & \vdots & \vdots & \vdots & \vdots & \vdots & \vdots \\
a_{m 1} & a_{m 2} & a_{m 3} & \cdots & a_{m j} & \cdots & a_{m n}
\end{array}\right]
$$

- matrix of coefficients of the constraint system of the primal problem;

$$
\mathbf{b}=B=b=\left[\begin{array}{c}
b_{1} \\
b_{2} \\
\vdots \\
b_{m}
\end{array}\right]=\left[b_{1}, b_{2}, \ldots, b_{m}\right]^{T}, \quad B \in \mathbf{R}^{m}
$$

- coefficients of the right sides of the constraint system of the primal problem;

$$
\mathbf{y}=Y=y=\left[\begin{array}{c}
y_{1} \\
y_{2} \\
\vdots \\
y_{m}
\end{array}\right]=\left[y_{1}, y_{2}, \ldots, y_{m}\right]^{T}, \quad Y \in \mathbf{R}^{m}
$$

- variable (unknown) values of the dual LP problem.

We introduce systems of covariance and contravariance vectors for consideration [17]:

$$
\mathbf{a}_{j}=a_{j}=\left[\begin{array}{c}
a_{1 j} \\
a_{2 j} \\
\vdots \\
a_{n j}
\end{array}\right]=\left[a_{1 j}, a_{2 j}, \ldots, a_{n j}\right]^{T} \in \mathbf{R}^{m}, \quad j=1,2, \ldots, m
$$

- column vectors (covariance vectors) of the matrix $A$ of the constraint system $\Omega_{\mathrm{I}}$ of the primal problem;

$$
\mathbf{a}^{i}=a^{i}=\left[a_{i 1}, a_{i 2}, \ldots, a_{i n}\right] \in \mathbf{R}^{n}, \quad i=1,2, \ldots, n
$$

- row vectors (contravariance) of the matrix $A$ of the constraint system $\Omega_{\text {I }}$ of the primal problem.
In this case, the matrix $A$ of system coefficients can be presented in vector form:

$$
A=\left[\begin{array}{c}
\mathbf{a}^{1} \\
\mathbf{a}^{2} \\
\vdots \\
\mathbf{a}^{m}
\end{array}\right]=\left[\mathbf{a}^{1}, \mathbf{a}^{2}, \ldots, \mathbf{a}^{m}\right]^{\mathrm{T}}=\left[\mathbf{a}_{1}, \mathbf{a}_{2}, \ldots, \mathbf{a}_{n}\right] \in \mathbf{R}^{m} \otimes \mathbf{R}^{n},
$$

and the pair of dual problems has a third form:

$$
\mid \begin{aligned}
& \mathrm{W}_{\mathrm{I}}=(\mathbf{c}, \mathbf{x}) \rightarrow \max \\
& \Omega_{\mathrm{I}}:\left(\mathbf{a}_{j}, \mathbf{x}\right) \leq \mathbf{b}, \\
& \mathbf{x} \geq 0,
\end{aligned}
$$

- primal problem;

$$
\mid \begin{aligned}
& \mathrm{W}_{\mathrm{II}}=(\mathbf{b}, \mathbf{y}) \rightarrow \min , \\
& \Omega_{\mathrm{II}}:\left(\mathbf{a}^{i}, \mathbf{y}\right) \geq \mathbf{c}, \\
& \mathbf{y} \geq 0 .
\end{aligned}
$$

- dual problem to the given primal one.

In summary, we finally have three forms of the definition of the dual problem to the standard LP problem:

$$
\begin{aligned}
& \mathrm{I}: \mid \begin{array}{l}
W_{\mathrm{I}}=\sum_{j=1}^{n} c_{j} x_{j} \rightarrow \max , \\
\Omega_{\mathrm{I}}: \sum_{j=1}^{n} a_{i j} x_{j} \leq b_{i}, \quad i=1, \ldots, m, \stackrel{\text { def Dual }}{\longrightarrow} \\
x_{j} \geq 0, j=1, \ldots, n,
\end{array} \\
& \stackrel{\text { def Dual }}{\longrightarrow} \mathrm{II}: \mid \begin{array}{l}
W_{\mathrm{II}}=\sum_{i=1}^{m} b_{i} y_{i} \rightarrow \min , \\
\Omega_{\mathrm{II}}: \sum_{i=1}^{m} a_{i j} y_{i} \geq c_{j}, j=1,2, \ldots, n, \\
y_{i} \geq 0, i=1,2, \ldots, m,
\end{array} \\
& \mathrm{I}:\left|\begin{array}{l}
W_{\mathrm{I}}=C X \rightarrow \text { max, } \\
\Omega_{\mathrm{I}}: A X \leq B, \quad \stackrel{\text { def Dual }}{\longrightarrow} \mathrm{II}: \\
X \geq 0,
\end{array}\right| \begin{array}{l}
W_{\mathrm{II}}=Y B-\min , \\
\Omega_{\mathrm{II}}: Y A \geq C^{\mathrm{T}}, \\
Y \geq 0,
\end{array}
\end{aligned}
$$

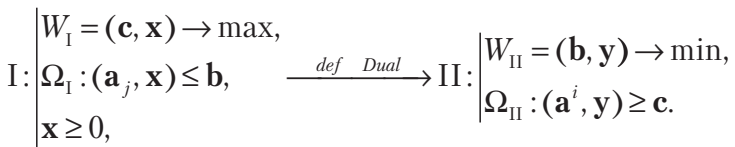

The conjugacy or duality of the given definition is justified by a certain sequence of operations, which, in the case of cyclic application, should lead to the primal problem, that is:

$$
\mathrm{I} \stackrel{\text { def Dual }}{\longrightarrow} \mathrm{II} \stackrel{\text { def Dual }}{\longrightarrow} \mathrm{I},
$$

where $\stackrel{\text { def Dual }}{\longrightarrow}$ is a set of rules of primal to dual conversion.

Careful analysis of the definition of the dual problem for standard form of representation of the primal problem allows determining necessary, for primal to dual conversion, operations $\stackrel{\text { def Dual }}{\longrightarrow}$ :

- extreme requirements of the objective functions of primal and dual problems are opposite:

$$
W_{\mathrm{I}} \rightarrow \max \stackrel{\text { def Dual }}{\longrightarrow} W_{\mathrm{II}} \rightarrow \min ;
$$


- for the max problem of the objective function, the inequalities in the constraint system must have the sign $\leq$ :

$$
\sum_{j=1}^{n} a_{i j} x_{j} \leq b_{i}
$$

- components of the objective function of the dual problem are components of the vector of the right sides of the constraint system of the primal LP problem;

- the matrix $A^{\mathrm{T}}$ of the constraint system of the dual problem $\Omega_{\text {II }}$ is transposed to the matrix $A$ of the constraint system of the primal problem $\Omega_{\mathrm{I}}$, since $Y A=A^{\mathrm{T}} Y^{\mathrm{T}}$;

- parts of the constraint system of the dual problem: $\Omega_{\mathrm{II}}:\left(\mathbf{a}^{i}, \mathbf{y}\right) \geq \mathbf{c}$ are coefficients of the objective function $W_{\mathrm{I}}=$ $=(\mathbf{c}, \mathbf{x}) \rightarrow$ max of the primal problem;

- each inequality constraint of the constraint system of the primal problem is put in correspondence with the non-negative dual unknown:

$$
\Omega_{\mathrm{I}}: \sum_{j=1}^{n} a_{i j} x_{j} \leq b_{i} \stackrel{\text { def Dual }}{\longrightarrow} y_{j} \geq 0, \quad i=1, \ldots, m ;
$$

- each non-negative unknown of the primal LP problem is put in correspondence with the inequality constraint of dual:

$$
x_{j} \geq 0 \stackrel{\text { def Dual }}{\longrightarrow} \Omega_{\mathrm{II}}: \sum_{i=1}^{m} a_{i j} y_{i} \geq c_{j}, \quad j=1,2, \ldots, n .
$$

Note that different forms of LP problems are equivalent. They keep a set of solutions. This can be achieved by using equivalent transformation techniques of conversion of one form of problems to another.

Thus, a certain equation of the constraint system of the LP problem is equivalent to a system of two inequalities:

$$
\sum_{j=1}^{n} a_{i j} x_{j}=b_{i} \Leftrightarrow\left\{\begin{array}{l}
\sum_{j=1}^{n} a_{i j} x_{j} \leq b_{i}, \\
-\sum_{j=1}^{n} a_{i j} x_{j} \leq-b_{i} .
\end{array}\right.
$$

Random sign variables can be presented as a difference of 2 non-negative variables:

$$
x_{j}=u_{j}-v_{j}, \quad u_{j} \geq 0, \quad v_{j} \geq 0 .
$$

Conversion of inequality constraints to equality constraints is done by adding the non-negative (balance) variable:

$$
\sum_{j=1}^{n} a_{i j} x_{j} \leq b_{j} \Rightarrow \sum_{j=1}^{n} a_{i j} x_{j}+x_{n+i}=b_{i}, \quad x_{n+i} \geq 0, \quad i=1, \ldots, k .
$$

To simplify the transformation of LP problems into different forms, conversion between maximization and minimization of the objective function and vice versa is also used:

$$
W_{\mathrm{I}}=\sum_{j=1}^{n} c_{j} x_{j} \rightarrow \max \Leftrightarrow W_{\mathrm{I}}=-\sum_{j=1}^{n} c_{j} x_{j} \rightarrow \min .
$$

Let us make sure that the introduced operations and transformations perform the conjugation chain for the above pair of problems:

$$
\mathrm{I} \stackrel{\text { def Dual }}{\longrightarrow} \mathrm{II} \stackrel{\text { def Dual }}{\longrightarrow} \mathrm{I} .
$$

Let us present the dual problem as a maximization problem and, by applying conversion rules and equivalent trans- formations, prove the conjugacy of the pair of problems - the dual problem of dual gives the original primal problem.

$$
\begin{aligned}
& W_{\mathrm{II}}=-Y B-\max , \\
& \text { II: } \Omega_{\text {II }}:-Y A \leq-C^{\mathrm{T}}, \stackrel{\text { def Dual }}{\longrightarrow} \\
& Y \geq 0 \text {, } \\
& W_{\mathrm{I}}=-\left(C^{\mathrm{T}}\right)^{\mathrm{T}} X-\min , \\
& \stackrel{\text { def Dual }}{\longrightarrow} \text { I: } \Omega_{\mathrm{I}}:-A X \leq-B, \quad \Leftrightarrow \\
& X \geq 0 \text {, } \\
& W_{\mathrm{I}}=C X-\max , \\
& \Leftrightarrow \mathbf{I}: \Omega_{\mathrm{I}}:-A X \leq-B, \\
& X \geq 0 \text {. }
\end{aligned}
$$

Thus, it is confirmed that the main feature of duality of pairs of LP problems is the possibility to reduce them to

\begin{tabular}{|c|c|c|c|c|c|c|c|c|c|}
\hline$Y \backslash X$ & $x_{1} \geq 0$ & $x_{2} \geq 0$ & $x_{3} \geq 0$ & $x_{4} \geq 0$ & $x_{5} \geq 0$ & $x_{6} \geq 0$ & $x_{7} \geq 0$ & $?$ & $B$ \\
\hline$y_{1} \geq 0$ & 3 & 0 & -4 & -7 & 5 & -4 & -1 & $\leq$ & 12 \\
\hline$y_{2} \geq 0$ & 1 & -1 & 3 & -2 & 0 & 7 & 9 & $\leq$ & 3 \\
\hline$y_{3} \geq 0$ & -5 & 3 & 0 & -8 & 5 & -9 & -4 & $\leq$ & -2 \\
\hline$y_{4} \geq 0$ & -7 & 5 & 9 & 1 & 3 & 0 & 1 & $\leq$ & -3 \\
\hline$?$ & $\geq$ & $\geq$ & $\geq$ & $\geq$ & $\geq$ & $\geq$ & $\geq$ & & \\
\hline$C$ & -4 & 2 & -3 & -8 & 1 & -1 & 5 & & \\
\hline
\end{tabular}
each other by definition (the dual of the dual is the primal problem).

\section{1. Model example No. 1}

To the primal linear programming problem:

$$
\mathbf{I}:\left\{\begin{array}{l}
W_{\mathrm{I}}=-4 x_{1}+2 x_{2}-3 x_{3}-8 x_{4}+x_{5}-x_{6}+5 x_{7}-\max , \\
\Omega_{\mathrm{I}}:\left\{\begin{array}{l}
3 x_{1}-4 x_{3}-7 x_{4}+5 x_{5}-4 x_{6}-x_{7} \leq 12, \\
x_{1}-x_{2}+3 x_{3}-2 x_{4}+7 x_{6}+9 x_{7} \leq 3, \\
5 x_{1}-3 x_{2}+8 x_{4}-5 x_{5}+9 x_{6}+4 x_{7} \geq 2, \\
7 x_{1}-5 x_{2}-9 x_{3}+x_{4}-3 x_{5}-x_{7} \geq 3,
\end{array}\right. \\
x_{j} \geq 0, j=1, \ldots, 7
\end{array}\right.
$$

formulate a dual problem.

Solution. To begin primal to dual conversion, we prepare a system of constraints. The maximization problem requires inequalities of the form $\leq$. In view of this, it is necessary to change the sign of the third and fourth inequalities to the opposite, multiplying by (-1).

$$
\mathbf{I}:\left\{\begin{array}{l}
W_{\mathrm{I}}=-4 x_{1}+2 x_{2}-3 x_{3}-8 x_{4}+x_{5}-x_{6}+5 x_{7}-\max , \\
\begin{array}{l}
3 x_{1}-4 x_{3}-7 x_{4}+5 x_{5}-4 x_{6}-x_{7} \leq 12, \\
x_{1}-x_{2}+3 x_{3}-2 x_{4}+7 x_{6}+9 x_{7} \leq 3, \\
-5 x_{1}+3 x_{2}-8 x_{4}+5 x_{5}-9 x_{6}-4 x_{7} \leq-2, \\
-7 x_{1}+5 x_{2}+9 x_{3}-x_{4}+3 x_{5}+x_{7} \leq-3,
\end{array} \\
x_{j} \geq 0, j=1, \ldots, 7 .
\end{array}\right.
$$

Primal to dual conversion is convenient to perform in Table 1.

Table 1

Primal to dual conversion for the model example No. 1

Following the primal to dual algorithm, we fill Table 1. Presentation of the primal problem in standard form has the following dual problem: 


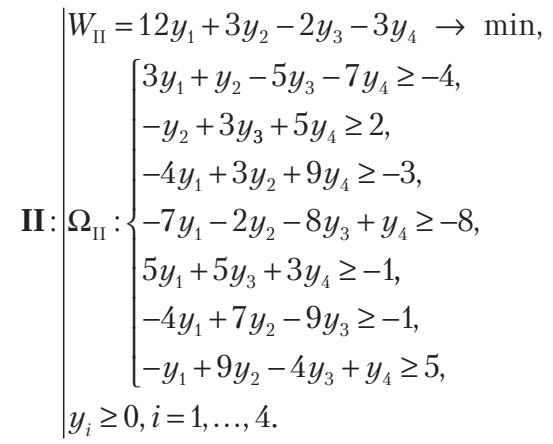

To obtain a complete set of primal to dual conversion operations, we consider the following pair of LP problems and prove their conjugacy.

$$
\mathrm{I}:\left|\begin{array}{l}
W_{\mathrm{I}}=C X-\max , \quad \text { def Dual } \\
\Omega_{\mathrm{I}}: A X=B,
\end{array} \mathrm{II}:\right| \begin{aligned}
& W_{\mathrm{I}}=Y B-\min , \\
& \Omega_{\mathrm{II}}: Y A=C^{\mathrm{T}} .
\end{aligned}
$$

Proof.

$$
\begin{aligned}
& \mathrm{I}: \mid \begin{array}{l}
W_{\mathrm{I}}=C X-\max , \quad X=X^{\prime \prime}-X^{\prime}, X^{\prime \prime} \geq 0, X^{\prime} \geq 0 \\
\Omega_{\mathrm{I}}: A X=B,
\end{array} \\
& \stackrel{X=X^{\prime \prime}-X^{\prime}, X^{\prime \prime} \geq 0, X^{\prime} \geq 0}{\longrightarrow} \mathrm{I}: \mid \begin{array}{l}
W_{\mathrm{I}}=C\left(X^{\prime \prime}-X^{\prime}\right)-\max , \\
\Omega_{\mathrm{I}}:\left\{\begin{array}{l}
A\left(X^{\prime \prime}-X^{\prime}\right) \leq B, \\
-A\left(X^{\prime \prime}-X^{\prime}\right) \leq-B, \\
X^{\prime \prime} \geq 0, X^{\prime} \geq 0,
\end{array}\right.
\end{array} \\
& \stackrel{\text { def Dual }}{\longrightarrow} \mathrm{II}: \mid \begin{array}{l}
W_{\mathrm{II}}=\left(Y^{\prime \prime}-Y^{\prime}\right) B-\min , \\
\Omega_{\mathrm{II}}:\left\{\begin{array}{l}
\left(Y^{\prime \prime}-Y^{\prime}\right) A \geq C^{\mathrm{T}}, \\
\left(Y^{\prime \prime}-Y^{\prime}\right)(-A) \geq-C^{\mathrm{T}}, \\
Y^{\prime \prime} \geq 0, Y^{\prime} \geq 0,
\end{array}\right.
\end{array} \Leftrightarrow \\
& \Leftrightarrow \mathrm{II}: \mid \begin{array}{l}
W_{\mathrm{I}}=Y B-\min , \\
\Omega_{\mathrm{II}}: Y A=C^{\mathrm{T}} .
\end{array}
\end{aligned}
$$

The proven duality of this pair of problems allows formulating the implications of the definition of duality for the standard LP problem:

- each equality constraint of the primal problem is put in correspondence with a random sign dual unknown;

$$
\mathrm{I}: \Omega_{\mathrm{I}}: A X=B \stackrel{\text { def Dual }}{\longrightarrow} \mathrm{II}: Y .
$$

where $Y$ is the random sign dual unknown;

- the random sign variable of the primal problem is put in correspondence with the equality constraint of the dual problem;

$$
\mathrm{I}: X \stackrel{\text { def Dual }}{\longrightarrow} \mathrm{II}: \Omega_{\mathrm{II}}: Y A=C^{\mathrm{T}} .
$$

where $X$ is the random sign variable of the primal problem:

Using similar transformations, it is possible to prove the conjugacy of the main asymmetric forms of pairs of dual problems:

$$
\mathrm{I}:\left|\begin{array}{l}
W_{\mathrm{I}}=C X-\max , \quad \text { def Dual } \\
\Omega_{\mathrm{I}}: A X \leq B,
\end{array} \mathrm{II}:\right| \begin{aligned}
& W_{\mathrm{II}}=Y B-\min , \\
& \Omega_{\mathrm{II}}: Y A=C^{\mathrm{T}}, \\
& Y \geq 0 .
\end{aligned}
$$

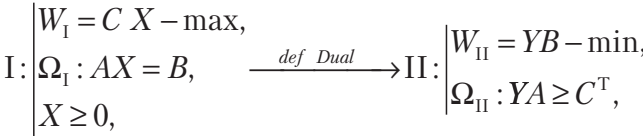

$$
\begin{aligned}
& \mathrm{I}:\left|\begin{array}{l}
W_{\mathrm{I}}=C X-\min , \quad \text { def Dual } \\
\Omega_{\mathrm{I}}: A X \geq B,
\end{array} \mathrm{II}:\right| \begin{array}{l}
W_{\mathrm{II}}=Y B-\max , \\
\Omega_{\mathrm{II}}: Y A=C^{\mathrm{T}}, \\
Y \geq 0 .
\end{array}
\end{aligned}
$$

Which was to be proved - the basic asymmetric forms of pairs of dual problems are conjugate.

\begin{tabular}{|c|c|c|c|c|c|c|c|}
\hline$Y \backslash X$ & $x_{1} \geq 0$ & $x_{2} \geq 0$ & $x_{3} \geq 0$ & $x_{4} \geq 0$ & $x_{5} \geq 0$ & $?$ & $B$ \\
\hline$y_{1}$ & -1 & -5 & -1 & -1 & 1 & $=$ & -41 \\
\hline$y_{2}$ & 0 & 4 & 1 & 0 & -1 & $=$ & 28 \\
\hline$y_{3}$ & 1 & 0 & 0 & -1 & 1 & $=$ & 9 \\
\hline$?$ & $\geq$ & $\geq$ & $\geq$ & $\geq$ & $\geq$ & & \\
\hline$C$ & 4 & 9 & 1 & 2 & -1 & & \\
\hline
\end{tabular}

\section{3. Model example No. 2}

To the primal linear programming problem:

$$
\mathbf{I}:\left\{\begin{array}{l}
W_{\mathrm{I}}=4 x_{1}+9 x_{2}+x_{3}+2 x_{4}-x_{5}-54 \rightarrow \max , \\
\Omega_{\mathrm{I}}:\left\{\begin{array}{l}
-x_{1}-5 x_{2}-x_{3}-x_{4}+x_{5}=-41, \\
4 x_{2}+x_{3}-x_{5}=28, \\
x_{1}-x_{4}+x_{5}=9,
\end{array}\right. \\
x_{j} \geq 0, j=1, \ldots, 5
\end{array}\right.
$$

formulate a dual problem.

Solution. We have the canonical form of the primal problem. For primal to dual conversion, we compile Table 2.

Table 2

Primal to dual conversion for model example No. 2

Following the primal to dual algorithm in case of presentation of the primal problem in the canonical form, we have the following dual problem:

$$
\mathbf{I I}: \mid \begin{aligned}
& \boldsymbol{W}_{\mathrm{II}}=-41 y_{1}+28 y_{2}+9 y_{3} \rightarrow \mathrm{min}, \\
& : \begin{array}{l}
-y_{1}+y_{3} \geq 4, \\
-5 y_{1}+4 y_{3} \geq 9, \\
-y_{1}+y \geq 1, \\
-y_{1}-y_{3} \geq 2, \\
y_{1}-y_{3}+y_{3} \geq-1, \\
y_{i} \geq 0, i=1,2,3 .
\end{array}
\end{aligned}
$$

The resulting form of the dual problem corresponds to the primal problem. That is, in case of presentation of the primal problem in the canonical form, it is possible to obtain the form of the dual problem.

\section{4. Model example No. 3}

To the primal linear programming problem:

$$
\mathbf{I}:\left\{\begin{array}{l}
W_{\mathrm{I}}=x_{1}-3 x_{2}+5 x_{3}+2 x_{4} \rightarrow \mathrm{min}, \\
\Omega_{\mathrm{I}}:\left\{\begin{array}{l}
4 x_{1}-5 x_{2}+3 x_{3}-x_{4} \geq 3 \\
-x_{1}+2 x_{2}+4 x_{3}-7 x_{4} \geq 2, \\
3 x_{1}-x_{2}-x_{3}-7 x_{4} \geq 3 \\
x_{1}+8 x_{2}-5 x_{3}-9 x_{4} \geq 8
\end{array}\right.
\end{array}\right.
$$

formulate a dual problem. 
Solution. For primal to dual conversion, we compile Table 3.

Table 3

Primal to dual conversion for model example No. 3

\begin{tabular}{|c|c|c|c|c|c|c|}
\hline$Y \backslash X$ & $x_{1}$ & $x_{2}$ & $x_{3}$ & $x_{4}$ & $?$ & $B$ \\
\hline$y_{1} \geq 0$ & 4 & -5 & 3 & -1 & $\geq$ & 3 \\
\hline$y_{2} \geq 0$ & -1 & 2 & 4 & -7 & $\geq$ & 2 \\
\hline$y_{3} \geq 0$ & 3 & -1 & -1 & -7 & $\geq$ & 3 \\
\hline$y_{4} \geq 0$ & 1 & 8 & -5 & -9 & $\geq$ & 8 \\
\hline$?$ & $=$ & $=$ & $=$ & $=$ & \multicolumn{1}{|}{} \\
\cline { 1 - 4 }$C$ & 1 & -3 & 5 & 2 &
\end{tabular}

Following the primal to dual algorithm, we have the following dual problem:

$$
\mathbf{I I}:\left\{\begin{array}{l}
\boldsymbol{I}_{\mathrm{II}}=3 y_{1}+2 y_{2}+3 y_{3}+8 y_{4} \rightarrow \max \\
:\left\{\begin{array}{l}
4 y_{1}-y_{2}+3 y_{3}+y_{4}=1 \\
-5 y_{1}+2 y_{2}-y_{3}+8 y_{4}=-3 \\
3 y_{1}+4 y_{2}-y_{3}-5 y_{4}=5 \\
-y_{1}-7 y_{2}-7 y_{3}-9 y_{4}=2
\end{array}\right. \\
y_{i} \geq 0, i=1,2,3,4
\end{array}\right.
$$

put in accordance with the original (primal) problem. It is confirmed that the dual problem corresponds to the primal problem. That is, in case of presentation of the primal problem in the canonical form, it is possible to obtain the form of the dual problem.

\section{5. Model example No. 4}

To the primal linear programming problem:

$$
\mathbf{I}: \mid \begin{aligned}
& W_{\mathrm{I}}=2 x_{1}+8 x_{2}-x_{3}+5 x_{4} \rightarrow \max , \\
& \Omega_{\mathrm{I}}:\left\{\begin{array}{l}
4 x_{1}-5 x_{2}+3 x_{3}-x_{4} \leq 3, \\
-x_{1}+2 x_{2}+4 x_{3}-7 x_{4} \leq 2
\end{array}\right.
\end{aligned}
$$

formulate a dual problem.

Solution. For primal to dual conversion, we compile Table 4.

Table 4

Primal to dual conversion for model example No. 4

\begin{tabular}{|c|c|c|c|c|c|c|}
\hline$Y \backslash X$ & $x_{1}$ & $x_{2}$ & $x_{3}$ & $x_{4}$ & $?$ & $B$ \\
\hline$y_{1} \geq 0$ & 4 & -5 & 3 & -1 & $\leq$ & 3 \\
\hline$y_{2} \geq 0$ & -1 & 2 & 4 & -7 & $\leq$ & 2 \\
\hline$?$ & $=$ & $=$ & $=$ & $=$ & \multicolumn{1}{|l}{} \\
\hline$C$ & 2 & 8 & -1 & 5 & &
\end{tabular}

Following the primal to dual algorithm, we have the following dual problem:

$$
\text { II : } \begin{aligned}
& \Omega_{\mathrm{II}}:\left\{\begin{array}{l}
4 y_{1}-y_{2}=2 \\
-5 y_{1}+2 y_{2}=8 \\
3 y_{1}+4 y_{2}=-1 \\
-y_{1}-7 y_{2}=5
\end{array}\right. \\
& y_{i} \geq 0, i=1,2
\end{aligned}
$$

put in accordance with the original (primal) problem. The above conjugate pairs of dual problems are the basis for generalizing the properties of duality in linear programming systems in case of presentation of the primal problem in the general form.

\section{Dual problem for the general form of primal problem}

The given pairs of dual problems allow performing a generalization of the definition of duality in linear programming problems in case of presentation of the primal problem in the general form.

Let us have the general linear programming problem:

$$
\mathbf{I}:\left\{\begin{array}{l}
W_{\mathrm{I}}=C X \rightarrow \max , \\
\Omega_{\mathrm{I}}:\left\{\left(\begin{array}{ll}
A_{11} & A_{12} \\
A_{21} & A_{22}
\end{array}\right)\left(\begin{array}{l}
X_{1} \\
X_{2}
\end{array}\right)\left[\begin{array}{l}
\leq \\
=
\end{array}\right]\left(\begin{array}{l}
B_{1} \\
B_{2}
\end{array}\right),\right. \\
x_{j} \geq 0, j=1,2, \ldots, l,
\end{array}\right.
$$

or in expanded form:

$$
\mathbf{I}:\left\{\begin{array}{l}
W_{\mathrm{I}}=\sum_{j=1}^{n} c_{j} x_{j} \rightarrow \max , \\
\Omega_{\mathrm{I}}:\left\{\begin{array}{l}
\sum_{j=1}^{n} a_{i j} x_{j} \leq b_{i}, \quad i=1,2,3, \ldots k, \\
\sum_{j=1}^{n} a_{i j} x_{j}=b_{i}, \quad i=k+1, k+2, k+3, \ldots m,
\end{array}\right. \\
x_{j} \geq 0, \quad j=1,2, \ldots, l,
\end{array}\right.
$$

the dual problem to it is the problem of the following form:

$$
\mathbf{I I}: \mid \begin{aligned}
& W_{\mathrm{II}}=Y B \rightarrow \min , \\
& \Omega_{\mathrm{II}}:\left\{\left(\begin{array}{ll}
Y_{1} & Y_{2}
\end{array}\right)\left(\begin{array}{ll}
A_{11} & A_{12} \\
A_{21} & A_{22}
\end{array}\right)\left[\begin{array}{l}
\geq \\
=
\end{array}\right]\left(\begin{array}{l}
C_{1} \\
C_{2}
\end{array}\right),\right. \\
& y_{i} \geq 0, i=1,2, \ldots, k,
\end{aligned}
$$

or in another form:

$$
\text { II }: \mid \begin{aligned}
& W_{\mathrm{II}}=\sum_{i=1}^{m} b_{i} y_{i} \rightarrow \min , \\
& \Omega_{\mathrm{II}}:\left\{\begin{array}{l}
\sum_{i=1}^{m} y_{i} a_{i j} \geq c_{j}, \quad j=1,2,3, \ldots l, \\
\sum_{i=1}^{m} y_{i} a_{i j}=c_{i}, \quad i=l+1, l+2, l+3, \ldots n,
\end{array}\right. \\
& y_{i} \geq 0, i=1,2, \ldots, k .
\end{aligned}
$$

Model example No. 5

To the primal linear programming problem:

$$
\mathbf{I}:\left\{\begin{array}{l}
W_{\mathrm{I}}=7 x_{1}-4 x_{2}+3 x_{3}-2 x_{4}+x_{5} \rightarrow \min \\
\Omega_{\mathrm{I}}:\left\{\begin{array}{l}
-3 x_{1}-5 x_{2}+9 x_{3}-x_{4}+8 x_{5} \geq 24 \\
x_{1}+2 x_{2}-x_{3}+3 x_{4}-7 x_{5} \leq 11 \\
x_{1}+4 x_{2}+x_{3}-2 x_{4}-x_{5}=8 \\
-x_{1}+3 x_{2}+6 x_{3}-5 x_{4}-3 x_{5}=21
\end{array}\right. \\
x_{3} \geq 0, x_{5} \geq 0
\end{array}\right.
$$

formulate a dual problem.

Solution. For primal to dual conversion, we prepare a system of constraints of the primal problem - for the mini- 
mization problem it is necessary to have inequalities only $\geq$. We change the sign of the second inequality to the opposite.

$$
\mathbf{I}:\left\{\begin{array}{l}
W_{\mathrm{I}}=7 x_{1}-4 x_{2}+3 x_{3}-2 x_{4}+x_{5} \rightarrow \min \\
\Omega_{\mathrm{I}}:\left\{\begin{array}{l}
-3 x_{1}-5 x_{2}+9 x_{3}-x_{4}+8 x_{5} \geq 24 \\
-x_{1}-2 x_{2}+x_{3}-3 x_{4}+7 x_{5} \geq-11 \\
x_{1}+4 x_{2}+x_{3}-2 x_{4}-x_{5}=8 \\
-x_{1}+3 x_{2}+6 x_{3}-5 x_{4}-3 x_{5}=21
\end{array}\right. \\
x_{3} \geq 0, x_{5} \geq 0
\end{array}\right.
$$

Primal to dual conversion is performed in Table 5.

Table 5

Primal to dual conversion for model example No. 5

\begin{tabular}{|c|c|c|c|c|c|c|c|}
\hline$Y \backslash X$ & $x_{1}$ & $x_{2}$ & $x_{3} \geq 0$ & $x_{4}$ & $x_{5} \geq 0$ & $?$ & $B$ \\
\hline$y_{1} \geq 0$ & -3 & -5 & 9 & -1 & 8 & $\geq$ & 24 \\
\hline$y_{2} \geq 0$ & -1 & -2 & 1 & -3 & 7 & $\geq$ & -11 \\
\hline$y_{3}$ & 1 & 4 & 1 & -2 & -1 & $=$ & 8 \\
\hline$y_{4}$ & -1 & 3 & 6 & -5 & -3 & $=$ & 21 \\
\hline$?$ & $=$ & $=$ & $\leq$ & $=$ & $\leq$ & & \\
\hline$C$ & 7 & -4 & 3 & -2 & 1 & & \\
\hline
\end{tabular}

The dual problem has the following form:

$$
\text { II: }\left\{\begin{array}{l}
\Omega_{\mathrm{II}}=\left\{\begin{array}{l}
-3 y_{1}-y_{2}+y_{3}-y_{4}=7, \\
-5 y_{1}-2 y_{2}+4 y_{3}+3 y_{4}=-4, \\
9 y_{1}+y_{2}+y_{3}+5 y_{4} \leq 7, \\
y_{1}+3 y_{2}+2 y_{3}+5 y_{4}=2, \\
8 y_{1}+7 y_{2}-y_{3}-3 y_{4} \leq 7
\end{array}\right. \\
y_{1} \geq 0, y_{2} \geq 0 .
\end{array}\right.
$$

We investigate the case of the presence of non-positive unknowns in the primal problem and violation of the correspondence of the inequality sign to the extremum type of the objective function.

Let us prove that every non-positive unknown $x \leq 0$ of the primal problem is put in correspondence with the inequality constraint, for $\max -\geq$, and for $\min -\leq$.

The pair of LP problems are dual.

$$
\mathrm{I}:\left|\begin{array}{l}
W_{\mathrm{I}}=C X-\max , \quad \text { def Dual } \\
\Omega_{\mathrm{I}}: A X \geq B, \quad \mathrm{II}: \\
X \geq 0,
\end{array}\right| \begin{aligned}
& W_{\mathrm{II}}=Y B-\min , \\
& \Omega_{\mathrm{II}}: Y A \leq C^{\mathrm{T}}, \\
& Y \leq 0 .
\end{aligned}
$$

Indeed,

$$
\begin{aligned}
& W_{\mathrm{I}}=C X-\max ,_{\times(-1)} \mid W_{\mathrm{I}}=C X-\max , \\
& \mathbf{I}: \begin{array}{ll}
\Omega_{\mathrm{I}}: A X \geq B, \quad \stackrel{\times(-1)}{\Leftrightarrow} \mathrm{I}: & \begin{array}{l}
\Omega_{\mathrm{I}}:-A X \leq-B, \stackrel{\text { def Dual }}{\longrightarrow} \\
X \geq 0,
\end{array} \\
X \geq 0,
\end{array} \\
& \stackrel{\text { def Dual }}{\longrightarrow} \mathbf{I I}: \mid \begin{array}{l}
W_{\mathrm{II}}=Y^{\prime}(-B)-\min , \quad \\
\Omega_{\mathrm{II}}: Y^{\prime}(-A) \geq C^{\mathrm{T}}, \quad Y^{\prime}=-Y \\
Y^{\prime} \geq 0,
\end{array} \Leftrightarrow \begin{array}{l}
W_{\mathrm{II}}=Y B-\min , \\
\Omega_{\mathrm{II}}: Y A \leq C^{\mathrm{T}}, \\
Y \leq 0 .
\end{array}
\end{aligned}
$$

Thus, it is proved that in case of violation of the correspondence of the inequality sign to the optimum type of the objective function, the corresponding dual unknowns must be non-positive $y \leq 0$.
Similarly, it is found that every non-positive unknown $x \leq 0$ of the primal problem is put in correspondence with the inequality constraint in the dual problem, which is opposite in sign to the main definition. On these grounds, the given pairs of problems are dual.

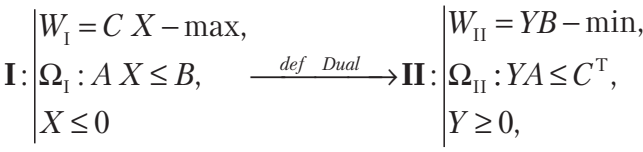

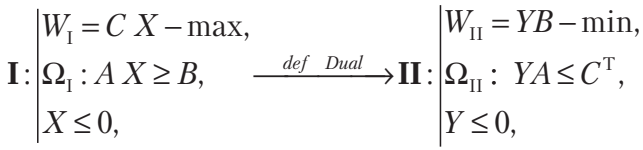

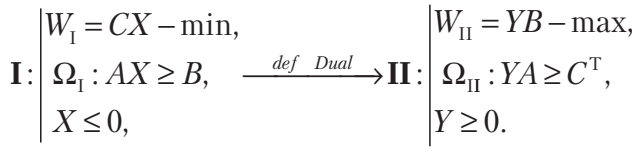

Thus, it is proved that every non-positive unknown $x \leq 0$ of the primal problem is put in correspondence with the inequality constraint in the dual problem, which is opposite in sign to the main definition. On these grounds, the given pairs of problems are dual to the original problems.

\section{Dual problem for an arbitrary form of the primal PL problem}

Summarizing the proofs and implications, it is possible to obtain a general primal to dual algorithm for an arbitrary form of the primal linear programming problem.

Definition. For an arbitrary form of the primal linear programming problem:

$$
\mathrm{I}: \mid \begin{aligned}
& W_{\mathrm{I}}=C X \rightarrow \max , \\
& \Omega_{\mathrm{I}}:\left\{\begin{array}{lll}
A_{11} & A_{12} & A_{13} \\
A_{21} & A_{22} & A_{23} \\
A_{31} & A_{32} & A_{33}
\end{array}\right)\left(\begin{array}{l}
X_{1} \\
X_{2} \\
X_{3}
\end{array}\right)\left[\begin{array}{l}
\leq \\
\geq \\
=
\end{array}\right]\left(\begin{array}{l}
B_{1} \\
B_{2} \\
B_{3}
\end{array}\right), \\
& x_{j} \geq 0, \quad j=1,2, \ldots, k, \\
& x_{j} \leq 0, \quad j=k+1, k+2, \ldots, l, \\
& x_{j}, \quad j=l+1, l+2, \ldots, n,
\end{aligned}
$$

or in expanded algebraic form:

$$
\mathbf{I}:\left\{\begin{array}{l}
W_{\mathrm{I}}=\sum_{j=1}^{n} c_{j} x_{j}-\max , \\
\Omega_{\mathrm{I}}: \begin{cases}\sum_{j=1}^{n} a_{i j} x_{j} \leq b_{i}, \quad i=1,2,3, \ldots, s, \\
\sum_{j=1}^{n} a_{i j} x_{j} \geq b_{i}, \quad i=s+1, s+2, s+3, \ldots, t, \\
\sum_{j=1}^{n} a_{i j} x_{j}=b_{i}, \quad i=t+1, t+2, t+3, \ldots, m, \\
x_{j} \geq 0, \quad j=1,2, \ldots, k, \\
x_{j} \leq 0, \quad j=k+1, k+2, \ldots, l, \\
x_{j}, \quad j=l+1, l+2, \ldots, n,\end{cases}
\end{array}\right.
$$

the dual problem to it is the problem of the following form: 


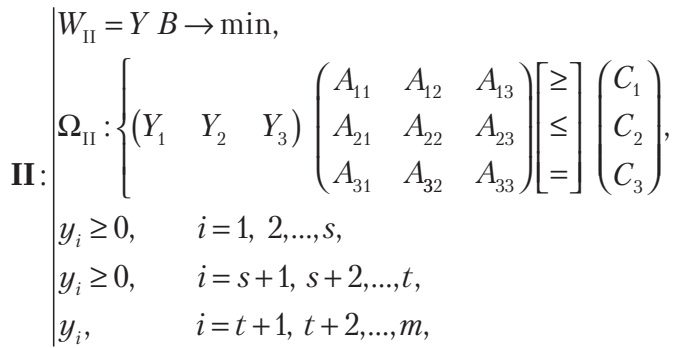

or in expanded algebraic form:

$$
\mathbf{I I}:\left\{\begin{array}{l}
\boldsymbol{W}_{\mathrm{II}}=\sum_{i=1}^{m} b_{i} y_{i}-\mathrm{min}, \\
: \begin{cases}\sum_{i=1}^{m} y_{i} a_{i j} \geq c_{j}, \quad j=1,2,3, \ldots k, \\
\sum_{i=1}^{m} y_{i} a_{i j} \leq c_{j}, \quad j=k+1, k+2, k+3, \ldots l, \\
\sum_{i=1}^{m} y_{i} a_{i j}=c_{i}, \quad i=l+1, l+2, l+3, \ldots n,\end{cases} \\
y_{i} \geq 0, \quad i=1,2, \ldots, s, \\
y_{i} \leq 0, \quad i=s+1, s+2, \ldots, t, \\
y_{i}, \quad i=t+1, t+2, \ldots, m .
\end{array}\right.
$$

\section{Model example No. 6}

Formulate a dual problem to the given primal linear programming problem:

$$
\begin{aligned}
& W_{\mathrm{I}}=7 x_{1}-4 x_{2}+9 x_{3}-2 x_{4}-\max , \\
& \left\{\begin{array}{l}
-2 x_{1}-3 x_{2}+5 x_{3}+x_{4}=1 \\
3 x_{1}+4 x_{2}-8 x_{3}-2 x_{4} \geq 21 \\
x_{1}-2 x_{2}-3 x_{3}+4 x_{4} \leq 12
\end{array}\right. \\
& x_{2} \leq 0, x_{4} \geq 0
\end{aligned}
$$

Solution. Primal to dual conversion is performed in Table 6 .

Table 6

Primal to dual conversion for model example No. 6

\begin{tabular}{|c|c|c|c|c|c|c|}
\hline$Y \backslash X$ & $x_{1}$ & $x_{2} \leq 0$ & $x_{3}$ & $x_{4} \geq 0$ & $?$ & $B$ \\
\hline$y_{1}$ & -2 & -3 & 5 & 1 & $=$ & 1 \\
\hline$y_{2} \leq 0$ & 3 & 4 & -8 & -2 & $\geq$ & 21 \\
\hline$y_{4} \geq 0$ & 1 & -2 & -3 & 4 & $\leq$ & 12 \\
\hline$?$ & $=$ & $\leq$ & $=$ & $\geq$ & \multicolumn{1}{|l}{} \\
\cline { 1 - 5 }$C$ & 7 & -4 & 9 & -2 & \multicolumn{1}{|l}{} \\
\cline { 1 - 4 } & &
\end{tabular}

The dual problem has the following form:

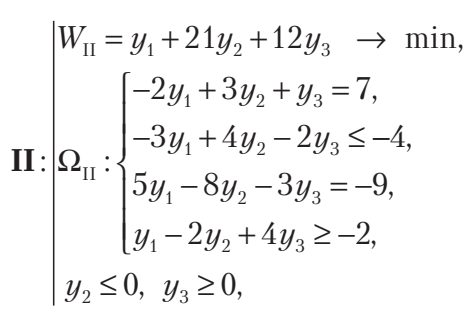

put in accordance with the original (primal) problem. That is, it is proved that for an arbitrary form of the primal linear programming problem, there is a general primal to dual algorithm.

\section{Discussion of the results of the study of dual problems}

As is known, the majority of LP problems are solved due to specific conditions or simplification using available constraints in the form of equalities or inequalities [5]. Sometimes it is possible to formulate problems of iterative search of the solution of systems of equations [12] or decompose systems using graphs [13]. Such methods of formulating LP problems and solving systems of linear equations use direct descriptions of systems with the construction of unique solution algorithms [15]. Despite the wide variety of forms of LP problems, it remains relevant to identify ways of generalizing the search for solutions. It is shown that, from the practical point of view, the proposed approach allows expanding the possibilities of choosing the form of LP problems in order to reduce the computing complexity of optimization problems of this class [18]. It is suggested to choose the simplest form at the stage of problem statement, taking into account available conjugated dual problem mappings.

Dual conjugated pairs of mappings of LP problems are formed through the inversion of the objective function and variables of the problem. The following rules for constructing a dual problem are known:

- each $i$-th constraint of the original problem corresponds to the variable $y_{i}$ of the dual problem; and vice versa, each $j$-th constraint of the dual problem corresponds to the variable $x_{j}$ of the original problem;

- if one of the pair of dual problems is formulated on maximization of the objective function, then the second - on minimization and vice versa;

- inequality constraints should be written with the sign «य»- in minimization of the objective function;

- coefficients of the objective function of one of the problems are free members of the constraint system of the other problem;

- matrices composed of the coefficients of the constraints of the original and dual problems are mutually transposed.

Optimal solutions to the dual problems are closely interconnected, which leads to the conclusion that, in the general case, there is no need to search for a solution by the description of both primal and dual conjugate problems. It is enough to define the solution only by one form of description.

For optimal solutions of the primal and dual problem, when inequality is strictly fulfilled, zero variables correspond to constraints, and non-zero variables included in the basis correspond to the conditions of the fuzzy constraint inequality, implemented as equality. These properties of dual solution can significantly reduce the time of solution, if the problem has much more constraints than variables. Then, solving the dual problem, it is possible to find its basis, and then, after selecting only the constraints in the primal problem corresponding to the basis, solve the ordinary system of linear equations for them.

The applied value of the proposed approach is the use of the obtained result to enable the improvement of complex systems described by systems of linear equations with systems of linear constraints [19]. A large number of mathematical models in project management have a description of linear optimization problems. In this regard, the given theoretical data are used to solve their conjugate problems, which have practical interpretation. Generalization of the method of mutual conjugacy of mathematical mappings of the dual problem for an arbitrary form of the primal problem will make it possible to easily obtain correct pairs of known 
dual problems. This allowed to propose and validate the algorithm for constructing the dual problem for an arbitrary form of primal problem. The main drawback or limitation of the proposed method is applicability only for linear problems.

\section{Conclusions}

1. For existing pairs of dual problems, their conjugacy as the main criterion for composing duality pairs is rigorously proved. Formation of the dual problem is based on the statement that the dual problem of dual is a primal (original) problem. For different pairs of dual problems, this statement is rigorously proved.

2. Operations of conversion of the primal problem to the dual problem presented in the general form are rigorously defined. Given this, primal to dual conversion has a simple formal order. This suggests that, in the general case, there is no need to search for a solution by the description of both primal and dual conjugate problems. It is sufficient to define the solution only by one form of description of the linear programming problem.

\section{References}

1. Drozd, J., Drozd, A. (2013). Models, methods and means as resources for solving challenges in co-design and testing of computer systems and their components. The International Conference on Digital Technologies 2013. doi: https://doi.org/10.1109/ dt.2013.6566307

2. Sigal, I. H., Ivanova, A. P. (2003). Vvedenie v prikladnoe diskretnoe programmirovanie: modeli i vychislitel'nye algoritmy. Moscow, 240.

3. Hetmantsev, V. D. (2001). Liniyna alhebra i liniyne prohramuvannia. Kyiv: Lybid, 250.

4. Teschl, G., Teschl, S. (2008). Mathematik für Informatiker. Band 1: Diskrete Mathematik und Lineare Algebra. Springer, 519. doi: https://doi.org/10.1007/978-3-540-77432-7

5. Biloshchytskyi, A., Myronov, O., Reznik, R., Kuchansky, A., Andrashko, Y., Paliy, S., Biloshchytska, S. (2017). A method to evaluate the scientific activity quality of HEIs based on a scientometric subjects presentation model. Eastern-European Journal of Enterprise Technologies, 6 (2 (90)), 16-22. doi: https://doi.org/10.15587/1729-4061.2017.118377

6. Tytov, S. D., Chernova, L. S. (2017). Vyshcha ta prykladna matematyka. Ch. 1. Kharkiv: Fakt, 336.

7. Nozicka, F., Guddat, J., Hollatz, H. (1972). Theorie der Linearen Optimierung. Berlin, 378.

8. Lau, D. (2011). Algebra und Diskrete Mathematik 1. Springer. doi: https://doi.org/10.1007/978-3-642-19443-6

9. Biloshchytskyi, A., Kuchansky, A., Andrashko, Y., Biloshchytska, S., Kuzka, O., Shabala, Y., Lyashchenko, T. (2017). A method for the identification of scientists' research areas based on a cluster analysis of scientific publications. Eastern-European Journal of Enterprise Technologies, 5 (2 (89)), 4-11. doi: https://doi.org/10.15587/1729-4061.2017.112323

10. Biloshchytskyi, A., Kuchansky, A., Biloshchytska, S., Dubnytska, A. (2017). Conceptual model of automatic system of near duplicates detection in electronic documents. 2017 14th International Conference The Experience of Designing and Application of CAD Systems in Microelectronics (CADSM). doi: https://doi.org/10.1109/cadsm.2017.7916155

11. Unger, N., Dempe, S. (2010). Lineare Optimierung. Springer. doi: https://doi.org/10.1007/978-3-8348-9659-9

12. Kolesnikov, O., Gogunskii, V., Kolesnikova, K., Lukianov, D., Olekh, T. (2016). Development of the model of interaction among the project, team of project and project environment in project system. Eastern-European Journal of Enterprise Technologies, 5 (9 (83)), 20-26. doi: https://doi.org/10.15587/1729-4061.2016.80769

13. Wu, C., Nikulshin, V. (2000). Method of thermoeconomical optimization of energy intensive systems with linear structure on graphs. International Journal of Energy Research, 24 (7), 615-623. doi: https://doi.org/10.1002/1099-114x(20000610)24:7<615\%:aider608>3.3.co;2-g

14. Kuchansky, A., Biloshchytskyi, A., Andrashko, Y., Biloshchytska, S., Shabala, Y., Myronov, O. (2018). Development of adaptive combined models for predicting time series based on similarity identification. Eastern-European Journal of Enterprise Technologies, 1 (4 (91)), 32-42. doi: https://doi.org/10.15587/1729-4061.2018.121620

15. Gogunskii, V., Kolesnikov, O., Kolesnikova, K., Lukianov, D. (2016). «Lifelong learning» is a new paradigm of personnel training in enterprises. Eastern-European Journal of Enterprise Technologies, 4 (2 (82)), 4-10. doi: https://doi.org/10.15587/ 1729-4061.2016.74905

16. Demin, D. (2017). Improvement of approaches to the construction of the training process of sportsmen, considered within the framework of the realization of informal education processes. ScienceRise: Pedagogical Education, 9 (17), 28-46. doi: https://doi.org/ 10.15587/2519-4984.2017.111110

17. Lax, P. D. (2013). Linear Algebra and Its Applications. Wiley, 392. Available at: https://www.wiley.com/en-us/Linear+Algebra+ and+Its+Applications\%2C+2nd+Edition-p-9781118626924

18. Drozd, J., Drozd, A., Maevsky, D., Shapa, L. (2014). The levels of target resources development in computer systems. Proceedings of IEEE East-West Design \& Test Symposium (EWDTS 2014). doi: https://doi.org/10.1109/ewdts.2014.7027104

19. Chernov, S., Titov, S., Chernova, L., Gogunskii, V., Chernova, L., Kolesnikova, K. (2018). Algorithm for the simplification of solution to discrete optimization problems. Eastern-European Journal of Enterprise Technologies, 3 (4 (93)), 34-43. doi: https://doi.org/ 10.15587/1729-4061.2018.133405 